Article

\title{
Is Customer Orientation of Employees Sustainable? A Moderated Mediation Analysis
}

\author{
Junya Cai ${ }^{1}$, Taiwen Feng ${ }^{2,3, *}$, Wenbo Jiang ${ }^{3}$ and Jiapei $\mathrm{Li}^{3}$ \\ 1 School of Economic and Management, Xi'an University of Technology, Xi'an 710054, China; \\ junyacai@126.com \\ 2 Business School, Shandong University (Weihai), Weihai 264209, China \\ 3 School of Management, Northwestern Polytechnical University, Xi'an 710072, China; \\ jiangwenbo@mail.nwpu.edu.cn (W.J.); ljp2015202111@sina.com (J.L.) \\ * Correspondence: typhoonfeng@gmail.com; Tel.: +86-135-7219-0964
}

Received: 8 June 2017; Accepted: 8 July 2017; Published: 10 July 2017

\begin{abstract}
While existing literature has addressed the benefits of customer orientation, less is known about its negative outcomes. This study investigates the mediating effect of emotional dissonance on the relationship between customer orientation and unethical decision-making, and whether this mediating effect is moderated by occupation. A sample of 727 doctors and nurses from three Chinese hospitals completed anonymous questionnaires regarding customer orientation, emotional dissonance, and unethical decision-making. Our findings reveal that the positive relationship between customer orientation and unethical decision-making is fully mediated by emotional dissonance. Furthermore, the mediating effect of emotional dissonance is moderated by occupation, which suggests that the mediating effect of emotional dissonance is stronger for doctors. This study contributes to our understanding of how and for whom customer orientation results in unethical decision-making, and suggests the need to take occupation into account in preventing the negative outcomes of customer orientation.
\end{abstract}

Keywords: customer orientation; unethical decision-making; emotional dissonance; occupational differences

\section{Introduction}

Previous literature has investigated the bright side of customer orientation by reporting several of its benefits. These studies indicated that customer orientation will improve job performance through encouraging collaborative exchanges and motivating organizational citizenship behaviors $[1,2]$. However, we cannot take for granted that customer orientation always has positive outcomes. In other words, whether the customer orientation of employees is sustainable remains a question to be answered. Customer orientation may also result in some unintended consequences which will offset its benefits [3,4]. For example, customer orientated employees may make unethical decisions that could potentially harm others while benefitting herself/himself in order to satisfy customer needs [5]. Thus, this study investigates the influence of customer orientation on unethical decision-making.

Unethical decision-making has drawn growing attention from organizations, governments, and other stakeholders [6-8]. However, how unethical decision-making is influenced by customer orientation is still unclear. The major goal of customer orientation is to respond to and fulfill customers' needs in a timely manner $[9,10]$. To achieve this goal, employees may deviate from moral requirements [11]. Drawing from social role theory (SRT), customer orientated employees maintain the obligation to achieve their goals, which may make them overemphasize these goals and increase their confidence in the moral legitimacy of making unethical decisions [12]. Thus, customer orientated employees are more likely to make unethical decisions. 
How is unethical decision-making influenced by customer orientation? Conservation of resources (COR) theory suggests that satisfying customer needs requires constant emotion regulation, which may exhaust employees' resources [13,14]. To regulate their emotions, the emotional dissonance of employees is enhanced because more efforts are involved [15]. According to the stress-strain-outcome model, emotional dissonance may result in undesired outcomes, such as unethical decision-making $[16,17]$. In this study, we examined the mediating role of emotional dissonance on the relationship between customer orientation and unethical decision-making. We also examined the moderating role of occupation difference in this relationship.

\section{Theory Development and Hypotheses}

In this study, we propose that customer orientation will be positively related to unethical decision-making through emotional dissonance, and that this mediating effect is further moderated by occupation. The conceptual model of this hypothesis is shown in Figure 1.

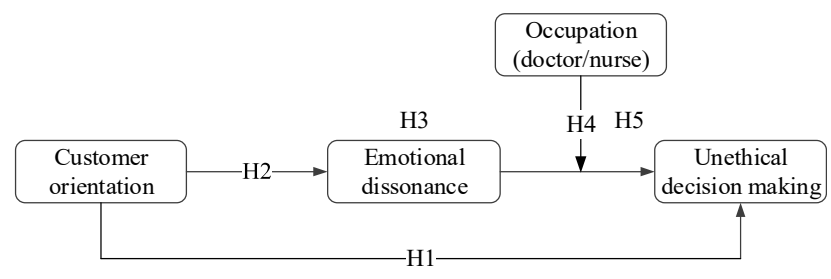

Figure 1. Conceptual model.

\subsection{The Mediating Role of Emotional Dissonance}

Customer orientation is defined as the extent to which employees are involved in behaviors identifying and meeting customer needs [1]. According to SRT, organizations set expectations for employees based on their social roles [18]. Thus, customer orientated employees are expected to treat customers with courtesy and satisfy all customer needs. However, achieving this goal is difficult in some conditions [19]. To realize the expected goals, most employees mainly focus on the outcomes of their behaviors, and do not care about the means [20]. In this situation, employees are likely to seek shortcuts, which may be not conducive to the sustainable development of their organizations [21]. Since result-orientation lessens the level of ethical recognition, employees may make more unethical decisions. Thus, we propose:

Hypothesis 1 (H1). Customer orientation will be positively related to unethical decision-making.

Emotional dissonance is defined as the difference between an employee's genuine feelings and the emotions that are requested in the workplace [22]. Both doctors and nurses are generally expected to display positive emotions during interactions with patients, such as empathy, care, and compassion [23]. However, doctors and nurses may experience negative feelings in the workplace, particularly when encountering excessive demands or unfriendly behaviors [22,24]. Therefore, to please customers and satisfy customer needs, doctors and nurses should cover up their negative emotions and show positive emotions toward patients [24,25].

Suggested by COR theory, employees that experience unreasonably demands and/or inadequate resources may display emotional dissonance [26]. Since doctors and nurses often are confronted with severe disease and death, their interactions with patients require excessive emotional resources [23]. In addition, doctors and nurses need to display different emotions in the workplace. For example, they should maintain a certain emotional distance toward patients to keep a professional attitude, as well as show a caring, compassionate, and empathizing attitude. Employees' emotional resources may become depleted, because a great amount of emotional resources are demanded to manage this diverse emotional work. If emotional resources are insufficient, employees are likely to hide their true feeling to make customers happy. According to above arguments, we hypothesize: 
Hypothesis 2 (H2). Customer orientation will be positively related to emotional dissonance.

According to COR theory, the emotional resources of employees will be inadequate to satisfy customer needs if they are emotional dissonant $[13,14]$. To meet customer needs, employees may make unethical decisions that would benefit themselves while potentially harming others. Thus, customer orientation will lead to emotional dissonance, which in turn, results in unethical decision-making. Based on the above discussion, we propose that:

Hypothesis 3 (H3). Emotional dissonance will mediate the relationship between customer orientation and unethical decision-making.

\subsection{The Moderating Role of Occupation}

Although customer orientation may result in unethical decision-making through triggering emotional dissonance, it is possible that doctors and nurses are not equally influenced. Previous studies have documented the important role of occupation in employees' emotional adaptation and unethical behaviors $[27,28]$. However, the potential differences between doctors and nurses concerning the relationships among customer orientation, emotional dissonance, and unethical decision-making are still open research questions. Thus, it is necessary to explore whether occupation moderates the mediating effect of emotional dissonance on the relationship between customer orientation and unethical decision-making.

Since nurses generally have more instructions to follow, the need for emotional resources will be less [27]. A suggested by COR theory, even they experience emotional dissonance, however, making unethical decisions is not their first choice [14]. In contrast, the medical work of doctors has fewer directives to be followed, which indicates that more emotional resources will be required to satisfy customer needs. In this case, the relationship between emotional dissonance and unethical decision-making will be strengthened for doctors. In addition, the medical work of doctors relies on more specialized knowledge than nurses. Because of information asymmetry between doctors and patients, the unethical behaviors of doctors are more difficult for others to detect. Thus, doctors are more likely to make unethical decisions when facing emotional dissonance. According to the above arguments, we hypothesize:

Hypothesis 4 (H4). Occupation will moderate the relationship between emotional dissonance and unethical decision-making. Specifically, the relationship will be much stronger for doctors than for nurses.

Hypothesis 5 (H5). Occupation will moderate the mediating effect of emotional dissonance on the relationship between customer orientation and unethical decision-making. Specifically, the indirect relationship will be much stronger for doctors than for nurses.

\section{Methods}

\subsection{Participants and Procedures}

Survey data from three hospitals located in Beijing, Xi'an, and Jinan, respectively, was collected. In each hospital, we identified a human resource manager to help us. A total of 1200 employees were randomly selected to participate in our survey. We then sent out the questionnaires to them. The questionnaires were coded before they were delivered to employees in order to match the responses across times. The use of the survey data was to be only for academic research, and anonymity of the participants was assured.

To mitigate the possible influence of common method bias, three waves of surveys were conducted [29]. At T1, the 1200 randomly selected employees were asked to communicate their gender, age, and tenure in the hospital, as well as their perceptions of customer orientation. At this stage, we received 756 usable questionnaires. Three months later (T2), we delivered questionnaires to the 756 employees who participated in the first survey. We requested them to report their perceptions of emotional dissonance in the workplace. At this stage, 738 usable questionnaires were received. 
Three months after the second survey (T3), questionnaires were sent to the 738 employees who took part in the second survey. We asked them to provide information related to unethical decision-making. At this stage, we received valid questionnaires from 736 employees. Finally, we received 727 useful responses, resulting in a response rate of $60.6 \%$.

Of the 727 responses, 430 are doctors. For doctors, $44.4 \%$ are male, the average age is 31.7 years $(\mathrm{SD}=7.1)$, and the average tenure in the hospital is 8.2 years $(\mathrm{SD}=7.1)$. For nurses, only $1.7 \%$ are male, the average age is 29.7 years $(\mathrm{SD}=7.0)$, and the average tenure in the hospital is 8.4 years $(\mathrm{SD}=7.6)$.

\subsection{Measures}

In this study, we used a Chinese questionnaire which was translated from English. We measured all the items using a seven-point Likert scale ranging from $1=$ 'strongly disagree' to $7=$ 'strongly agree'. We listed the measurement items in Appendix A.

Customer orientation. We measured customer orientation using a five-item scale that was adapted from Reference [1]. These items reflect the extent to which employees are involved in behaviors identifying and meeting customer needs. Sample items are "Trying to help patients make decisions that will satisfy their needs", "I respond very quickly to patient requests", and "I always have the patient's best interest in mind". The Cronbach's alpha for the scale is 0.894 .

Emotional dissonance. We measured emotional dissonance using a five-item scale that was adopted from Reference [22]. Sample items are "I have to cover up my true feelings when dealing with patients", and "In my work, I have to be friendly with patients, even when I don't want to". The Cronbach's alpha for the scale is 0.903 .

Unethical decision-making. We measured unethical decision-making using a six-item scale that was adapted from Reference [11]. Sample items are "I would be willing to pass on incorrect information to others if it gave me a competitive advantage", and "I would be willing to do a favor for others if that meant I would get special treatment in the competition". The Cronbach's alpha for the scale is 0.972 .

Occupation. In this study, occupation was measured using a dummy variable, which codes doctor as " 1 " and codes nurse as " 0 ".

Control variables. Existing literature has suggested that an employee's unethical decision-making is likely to be influenced by demographic variables, such as gender, age, and tenure in the organization [6,30]. Thus, we controlled these variables in this study. We measured gender using a dummy variable, which codes male as " 1 " and codes female as " 0 ". Age and tenure in the hospital were self-reported in years. We used their natural logarithms in the final analysis.

\subsection{Reliability and Validity}

Cronbach's alpha values of all the constructs are higher than 0.80 . Furthermore, we computed composite reliability $(\mathrm{CR})$, and all the $\mathrm{CR}$ values are greater than 0.80 . Thus, the reliability of scales in this study was ensured.

Content validity, convergent validity, and discriminant validity were also assessed. We assured content validity by extensively reviewing literature, interviewing with practitioners and scholars, and conducting a pilot test. Confirmatory factor analysis was performed by linking each item with its intended construct and freely estimating the covariance among constructs. Suggested by the model fit indices (root mean square error of approximation (RMSEA) $=0.09$, comparative fit index $(\mathrm{CFI})=0.97$, non-normed fit index $(\mathrm{NNFI})=0.96$, standard root mean square residual $(\mathrm{SRMR})=0.06)$, the overall measurement model was acceptable. All the $t$-values of factor loadings were greater than 2 , further indicating satisfactory convergent validity. Moreover, average variance extracted (AVE) values were higher than 0.5 , which suggests good convergent validity.

We compared the AVE values with shared variance between different constructs to assess discriminant validity. Descriptive statistics and intercorrelations between variables are shown in Table 1 . The square root of the AVE value is greater than the correlation for each construct, suggesting that the scale items share common variance with their related constructs more than with the other constructs. 
Table 1. Descriptive statistics and intercorrelations between variables.

\begin{tabular}{|c|c|c|c|c|c|c|c|c|c|c|c|c|}
\hline \multirow{2}{*}{ Constructs } & \multicolumn{2}{|c|}{ All } & \multicolumn{2}{|c|}{ Doctors } & \multicolumn{2}{|c|}{ Nurses } & \multirow[b]{2}{*}{1} & \multirow[b]{2}{*}{2} & \multirow[b]{2}{*}{3} & \multirow[b]{2}{*}{4} & \multirow[b]{2}{*}{5} & \multirow[b]{2}{*}{6} \\
\hline & Mean & SD & Mean & SD & Mean & SD & & & & & & \\
\hline 1. Gender & 0.27 & 0.44 & 0.44 & 0.50 & 0.02 & 0.13 & - & & & & & \\
\hline 2. Age & 3.41 & 0.22 & 3.43 & 0.22 & 3.37 & 0.21 & $0.14^{* * *}$ & - & & & & \\
\hline 3. Tenure & 1.73 & 0.92 & 1.73 & 0.93 & 1.74 & 0.91 & 0.06 & $0.83^{* * *}$ & - & & & \\
\hline 4. Customer orientation & 5.37 & 1.00 & 5.29 & 0.99 & 5.48 & 1.00 & -0.03 & -0.04 & 0.01 & 0.57 & & \\
\hline 5. Emotional dissonance & 3.47 & 1.36 & 3.55 & 1.33 & 3.35 & 1.39 & 0.04 & $0.10^{* *}$ & $0.13^{* * *}$ & $0.16^{* * *}$ & 0.66 & \\
\hline 6. Unethical decision-making & 2.35 & 1.41 & 2.53 & 1.50 & 2.09 & 1.24 & $0.16^{* * *}$ & 0.05 & 0.06 & $0.21^{* * *}$ & $0.57^{* * * *}$ & 0.83 \\
\hline
\end{tabular}

Note: ${ }^{*} p<0.05 ;{ }^{* *} p<0.01 ;{ }^{* * *} p<0.001$; square root of AVE value is on the diagonal.

\section{Results}

To examine the hypotheses, we conducted several hierarchical linear regression analyses. The analysis results are presented in Table 2. In Models 1 and 4, we first entered the control variables including gender, age, and tenure. We then entered the independent and mediating variables to test the direct and mediating effects. In Models 6 and 7, we also entered the moderating variable and its interaction with emotional dissonance to test its moderating effect on the relationship between emotional dissonance and unethical decision-making. The dependent variables were emotional dissonance (Models 1-2), and unethical decision-making (Models 3-7), respectively.

Table 2. Results of the regression analysis.

\begin{tabular}{cccccccc}
\hline \multirow{2}{*}{ Variables } & \multicolumn{3}{c}{ Emotional Dissonance } & \multicolumn{5}{c}{ Unethical Decision-Making } \\
\cline { 2 - 7 } & Model 1 & Model 2 & Model 3 & Model 4 & Model 5 & Model 6 & Model 7 \\
\hline Gender & 0.03 & 0.03 & $0.16^{* * *}$ & $0.16^{* * *}$ & $0.14^{* * *}$ & $0.12^{* *}$ & $0.12^{* * *}$ \\
Age & -0.06 & -0.06 & -0.05 & -0.05 & -0.02 & -0.04 & -0.03 \\
Tenure & $0.18^{* *}$ & $0.18^{* *}$ & 0.10 & 0.09 & -0.01 & 0.01 & 0.01 \\
Customer orientation & & $0.13^{*}$ & & $0.18^{* *}$ & 0.03 & 0.01 & 0.01 \\
Emotional dissonance & & & & & $0.57^{* * *}$ & $0.57^{* * *}$ & $0.57^{* * *}$ \\
Occupation & & & & & & 0.05 & 0.05 \\
Emotional dissonance $\times$ Occupation & 0.02 & 0.03 & 0.03 & 0.04 & 0.35 & 0.35 & 0.37 \\
$R^{2}$ & & 0.01 & & 0.01 & 0.31 & 0.00 & 0.02 \\
$\Delta R^{2}$ & & $6.28^{* *}$ & & $8.06^{* *}$ & 353.23 & 1.97 & $10.5^{* * *}$ \\
\hline
\end{tabular}

Note: ${ }^{*} p<0.05 ;{ }^{* *} p<0.01 ;{ }^{* * *} p<0.001$.

As shown in Table 2, customer orientation is positively related to emotional dissonance $(\beta=0.13$, $p<0.05)$, emotional dissonance is positively related to unethical decision-making $(\beta=0.57, p<0.001)$, and customer orientation is positively related to unethical decision-making $(\beta=0.18, p<0.01)$. These findings indicate that emotional dissonance fully mediates the relationship between customer orientation and unethical decision-making. Thus, H1, H2, and $\mathrm{H} 3$ are supported. Moreover, the interaction of emotional dissonance and occupation reveals a significant impact on unethical decision-making $(\beta=0.12, p<0.01)$. This indicates that occupation moderates the relationship between emotional dissonance and unethical decision-making, providing support for $\mathrm{H} 4$. To facilitate the interpretation of this moderating effect, we plotted it for doctors and nurses respectively. Figure 2 reveals that the relationship between emotional dissonance and unethical decision-making is stronger for doctors. Simple slope tests indicate that the influence of emotional dissonance on unethical decision-making is much stronger for doctors. Thus, H4 is further supported. 


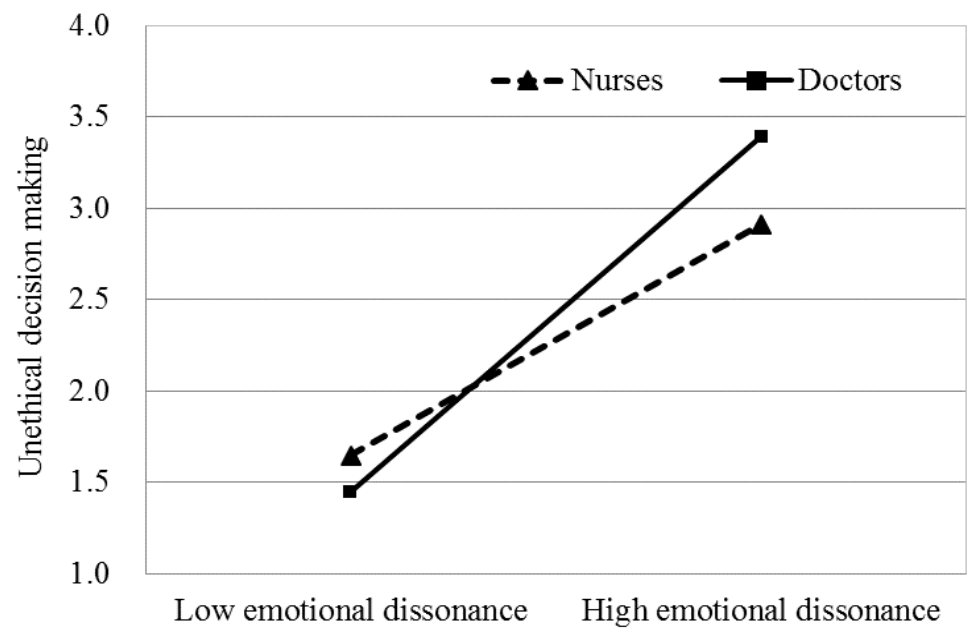

Figure 2. The moderating effect of occupation on the relationship between emotional dissonance and unethical decision-making.

To test the moderated mediating effect, a moderated path analysis was conducted [31], and bootstrapping 1000 samples were used to compute bias-corrected confidence intervals. As suggested by the results in Table 3, the difference of the indirect effect of emotional dissonance is 0.06 (doctors vs. nurses). The $95 \%$ confidence intervals computed using the bootstrap estimates exclude zero. Thus, the indirect effect of emotional dissonance is significant $(\Delta \beta=0.06, p<0.05)$, providing support for H5. Furthermore, the results presented in Table 3 reveal that occupation moderates the direct impact of emotional dissonance on unethical decision-making $(\Delta \beta=0.22, p<0.01)$, which provides further support for our theoretical argument that emotional dissonance interacts with occupation to influence unethical decision-making. Therefore, $\mathrm{H} 4$ receives further support.

Table 3. Results of the moderated mediating effect.

\begin{tabular}{lcccccc}
\hline & \multicolumn{5}{c}{ Customer Orientation $(\mathbf{X}) \rightarrow$ Emotional Dissonance (M) } \\
Moderator Variable & \multicolumn{5}{c}{\begin{tabular}{c} 
Enethical Decision-Making (Y) \\
\cline { 2 - 6 }
\end{tabular}} & \multicolumn{2}{c}{ Stage } & \multicolumn{3}{c}{ Effect } \\
\cline { 2 - 6 } & First & Second & Direct Effects & Indirect Effects & Total Effects \\
\cline { 2 - 6 } & $\boldsymbol{P}_{\mathbf{M X}}$ & $\boldsymbol{P}_{\mathbf{Y M}}$ & $\boldsymbol{P}_{\mathbf{Y X}}$ & $\boldsymbol{P}_{\mathbf{Y M}} \boldsymbol{P}_{\mathbf{M X}}$ & $\boldsymbol{P}_{\mathbf{Y X}}+\boldsymbol{P}_{\mathbf{Y M}} \boldsymbol{P}_{\mathbf{M X}}$ \\
\hline Simple paths for nurses & $0.12^{*}$ & $0.49^{* * *}$ & 0.04 & 0.07 & $0.11^{*}$ \\
Simple paths for doctors & $0.15^{*}$ & $0.71^{* *}$ & 0.02 & $0.13^{*}$ & $0.15^{*}$ \\
Differences & 0.03 & $0.22^{* *}$ & -0.02 & $0.06^{*}$ & 0.04 \\
\hline
\end{tabular}

Note: ${ }^{*} p<0.05 ;{ }^{* *} p<0.01 ;{ }^{* * *} p<0.001 . P_{\mathrm{MX}}$ : path from customer orientation to emotional dissonance; $P_{\mathrm{YM}}$ : path from emotional dissonance to unethical decision-making; $P_{Y X}$ : path from customer orientation to unethical decision-making. Tests of differences for the indirect and total effect were based on bias-corrected confidence intervals derived from bootstrap estimates.

\section{Discussion and Research Limitations}

This study examines the mediating role of emotional dissonance in the relationship between customer orientation and unethical decision-making, and explores whether this mediating effect is moderated by occupation. Thus, this study contributes to customer orientation literature by illustrating its negative outcomes and the moderating role of occupation on the links among customer orientation, emotional dissonance, and unethical decision-making. This study also improves our understanding of issues such as whether or not a mediating effect remains constant across different groups of individuals and whether occupational differences concern the relationships among customer orientation, emotional dissonance, and unethical decision-making. 
Consistent with the research hypotheses, our findings reveal that emotional dissonance plays an important mediating role in the relationship between customer orientation and unethical decision-making. Specifically, customer orientation has a positive impact on emotional dissonance, which in turn positively influences unethical decision-making. Our findings are also consistent with previous literature that suggests if employees experience negative emotions during customer interactions, they may engage in retaliatory behaviors [22].

In addition, we found that the indirect relationship between customer orientation and unethical decision-making through emotional dissonance is moderated by occupation, with the adverse effect of customer orientation being stronger for doctors compared with nurses. These findings are consistent with existing literature suggesting the occupational differences between doctors and nurses [27]. Our findings indicate that emotional dissonance influences doctors' unethical decision-making more seriously when they are requested to satisfy patients without considering the reasonableness and achievability of their needs.

This study has several limitations that should be further studied in future research. First, this study focuses on the mediating role of emotional dissonance. However, other emotional or cognitive variables may also exist to mediate the link between customer orientation and unethical decision-making. Future studies may examine the mediating roles of other intermediaries, such as emotional exhaustion and perceived work overload. Second, this study deems that unethical decision-making as an important undesired outcome of customer orientation, and examines how it is influenced by customer orientation. However, customer orientation may result in other unintended consequences, such as employees' retaliatory behaviors. Future research may investigate whether and how customer orientation can lead to other negative outcomes. Finally, this study investigates the moderating role of occupation in the mediation model using data collected from Chinese hospitals. The occupational differences that are identified may not be applied to other cultural contexts. Future studies should revalidate our findings by collecting data from different countries.

Acknowledgments: This work was supported by the Fundamental Research Funds for the Central Universities (3102016RW003).

Author Contributions: Junya Cai contributed reagents/materials/analysis tools; Taiwen Feng conceived and designed the experiment; Jiapei Li performed the experiments and analyzed the datas; Wenbo Jiang and Taiwen Feng wrote the paper.

Conflicts of Interest: The authors declare no conflict of interest.

\section{Appendix A. List of Measurement Items}

\section{Customer orientation}

CO1: Trying to help patients make decisions that will satisfy their needs.

CO2: I make every patient feel like he/she is the only patient.

CO3: I respond very quickly to patient requests.

CO4: I always have the patient's best interest in mind.

CO5: My number one priority is always patient satisfaction.

\section{Emotional dissonance}

ED1: I voice feelings to my patients that are different from what I feel inside.

ED2: I have to cover up my true feelings when dealing with patients.

ED3: I spend most of my work day hiding my true emotions.

ED4: I spend most of my work day faking positive emotions.

ED5: In my work I have to be friendly with patients, even when I don't want to. 


\section{Unethical decision-making}

UDM1: I would be willing to pass on incorrect information to others if it gave me a competitive advantage.

UDM2: I would be willing to engage in what some might say are sneaky tactics.

UDM3: I would be willing to do a favor for others if that meant I would get special treatment in the competition.

UDM4: I would be justified in misrepresenting the facts in order to preserve my integrity.

UDM5: I would be justified in making decisions that could potentially harm others while benefitting me.

UDM6: In order to achieve my goals, I would be justified in acting in defiance of laws, regulations, standards, and business codes if it is certain that no one will find out.

\section{References}

1. Korschun, D.; Bhattacharya, C.B.; Swain, S.D. Corporate social responsibility, customer orientation, and the job performance of frontline employees. J. Mark. 2014, 78, 20-37. [CrossRef]

2. Menguc, B.; Auh, S.; Katsikeas, C.S.; Jung, Y.S. When does (mis) fit in customer orientation matter for frontline employees' job satisfaction and performance? J. Mark. 2016, 80, 65-83. [CrossRef]

3. Homburg, C.; Müller, M.; Klarmann, M. When should the customer really be king? On the optimum level of salesperson customer orientation in sales encounters. J. Mark. 2011, 75, 55-74. [CrossRef]

4. Wetzel, H.A.; Hammerschmidt, M.; Zablah, A.R. Gratitude versus entitlement: A dual process model of the profitability implications of customer prioritization. J. Mark. 2014, 78, 1-19. [CrossRef]

5. Frow, P.; Payne, A.; Wilkinson, I.F.; Young, L. Customer management and CRM: Addressing the dark side. J. Serv. Mark. 2011, 25, 79-89. [CrossRef]

6. Kish-Gephart, J.J;; Harrison, D.A.; Treviño, L.K. Bad apples, bad cases, and bad barrels: Meta-analytic evidence about sources of unethical decisions at work. J. Appl. Psychol. 2010, 95, 1-31. [CrossRef] [PubMed]

7. Ogunfowora, B.; Bourdage, J.S.; Nguyen, B. An exploration of the dishonest side of self-monitoring: Links to moral disengagement and unethical business decision making. Eur. J. Personal. 2013, 27, 532-544. [CrossRef]

8. Umphress, E.E.; Bingham, J.B.; Mitchell, M.S. Unethical behavior in the name of the company: The moderating effect of organizational identification and positive reciprocity beliefs on unethical pro-organizational behavior. J. Appl. Psychol. 2010, 95, 769-780. [CrossRef] [PubMed]

9. Auh, S.; Menguc, B. Performance implications of the direct and moderating effects of centralization and formalization on customer orientation. Ind. Mark. Manag. 2007, 36, 1022-1034. [CrossRef]

10. Chuang, S.H.; Lin, H.N. The roles of infrastructure capability and customer orientation in enhancing customer-information quality in CRM systems: Empirical evidence from Taiwan. Int. J. Inf. Manag. 2013, 33, 271-281. [CrossRef]

11. Hoyt, C.L.; Price, T.L. Ethical decision making and leadership: Merging social role and self-construal perspectives. J. Bus. Ethics 2015, 126, 531-539. [CrossRef]

12. Hoyt, C.L.; Price, T.L.; Poatsy, L. The social role theory of unethical leadership. Leadersh. Q. 2013, 24, 712-723. [CrossRef]

13. Brotheridge, C.M.; Lee, R.T. Testing a conservation of resources model of the dynamics of emotional labor. J. Occup. Health Psychol. 2002, 7, 57-67. [CrossRef] [PubMed]

14. Grandey, A.A.; Dickter, D.N.; Sin, H.P. The customer is not always right: Customer aggression and emotion regulation of service employees. J. Org. Behav. 2004, 25, 397-418. [CrossRef]

15. Goussinsky, R. Customer aggression, emotional dissonance and employees' well-being. Int. J. Qual. Serv. Sci. 2011, 3, 248-266. [CrossRef]

16. Cheung, F.; Tang, C. The influence of emotional dissonance on subjective health and job satisfaction: Testing the stress-strain-outcome model. J. Appl. Soc. Psychol. 2010, 40, 3192-3217. [CrossRef]

17. Krishnakumar, S.; Rymph, D. Uncomfortable ethical decisions: The role of negative emotions and emotional intelligence in ethical decision-making. J. Manag. Issues 2012, 24, 321-344.

18. Zhao, W.X.; Wang, J.; He, Y.; Nie, J.Y.; Wen, J.R.; Li, X. Incorporating social role theory into topic models for social media content analysis. IEEE Trans. Knowl. Data Eng. 2015, 27, 1032-1044. [CrossRef]

19. Rego, L.L.; Morgan, N.A.; Fornell, C. Reexamining the market share-customer satisfaction relationship. J. Mark. 2013, 77, 1-20. [CrossRef] 
20. Flynn, F.J. Identity orientations and forms of social exchange in organizations. Acad. Manag. Rev. 2005, 30, 737-750. [CrossRef]

21. Zhang, Z.; Jia, M. How can companies decrease the disruptive effects of stretch goals? The moderating role of interpersonal-and informational-justice climates. Hum. Relat. 2013, 66, 993-1020. [CrossRef]

22. Madupalli, R.K.; Poddar, A. Problematic customers and customer service employee retaliation. J. Serv. Mark. 2014, 28, 244-255. [CrossRef]

23. Bakker, A.B.; Heuven, E. Emotional dissonance, burnout, and in-role performance among nurses and police officers. Int. J. Stress Manag. 2006, 13, 423-440. [CrossRef]

24. Xanthopoulou, D.; Bakker, A.B.; Fischbach, A. Work engagement among employees facing emotional demands. J. Pers. Psychol. 2013, 12, 74-84. [CrossRef]

25. Diefendorff, J.M.; Richard, E.M. Antecedents and consequences of emotional display rule perceptions. J. Appl. Psychol. 2003, 88, 284-294. [CrossRef] [PubMed]

26. Karatepe, O.M.; Aleshinloye, K.D. Emotional dissonance and emotional exhaustion among hotel employees in Nigeria. Int. J. Hosp. Manag. 2009, 28, 349-358. [CrossRef]

27. Kingston, M.J.; Evans, S.M.; Smith, B.J.; Berry, J.G. Attitudes of doctors and nurses towards incident reporting: A qualitative analysis. Med. J. Aust. 2004, 181, 36-39. [PubMed]

28. Lawton, R.; Parker, D. Barriers to incident reporting in a healthcare system. Qual. Saf. Health Care 2002, 11, 15-18. [CrossRef] [PubMed]

29. Podsakoff, P.M.; MacKenzie, S.B.; Lee, J.Y.; Podsakoff, N.P. Common method variance in behavioral research: A critical review of the literature and recommended remedies. J. Appl. Psychol. 2003, 88, 879-903. [CrossRef] [PubMed]

30. Craft, J.L. A review of the empirical ethical decision-making literature: 2004-2011. J. Bus. Ethics 2013, 117, 221-259. [CrossRef]

31. Edwards, J.R.; Lambert, L.S. Methods for integrating moderation and mediation: A general analytical framework using moderated path analysis. Psychol. Methods 2007, 12, 1-22. [CrossRef] [PubMed]

(C) 2017 by the authors. Licensee MDPI, Basel, Switzerland. This article is an open access article distributed under the terms and conditions of the Creative Commons Attribution (CC BY) license (http:/ / creativecommons.org/licenses/by/4.0/). 